\title{
A Human-Computer Interaction Approach for Integrity in Economics
}

\author{
Kweku Opoku-Agyemang
}

\begin{abstract}
Emerging data science platforms using simplified and automated user interfaces can help research become significantly more transparent and ethical. By depending on standard humangenerated code, many statistical software programs commonly used in economics and the social sciences inadvertently rely on the human willpower of scientists, and inspite of an assumed invincibility, such individuals are nearly necessarily prone to errors and research integrity compromises, as is increasingly clear. Removing the vast majority of arbitrary and subjective data judgments, including the generation of code, from researcher control would free behavioural and social scientists from human limitations. Automating the text annotations that accompany data visualizations in figures and diagrams using emerging natural language processing tools can also free scientists from overconfidence or the temptation to embellish findings. Scientific communities across economics as well as other social science fields should embrace such systems to enhance the integrity and transparency of the next-generation of research.
\end{abstract}

Subject terms: Research Transparency, Research Integrity, Research Ethics.

The much-touted replication crisis is causing much reflection across the academy, and with good reason. Failures to replicate research harm the integrity of knowledge. To protect science, scholars are focusing on the research process and rising to the challenge. Open data policies help encourage the replication of research by independent parties ${ }^{1}$. The provision of the specific code commands used to implement the analyses particularly help open conversations across research labs on research questions. Such code can make it easier to implement newer studies that are broadly related and even empower trainees with limited experience. Even more is being done to protect the integrity of science in general, while encouraging researchers to do more transparent work.

Ultimately, however, the elephant in the room is that the behavioral issues that motivate some scientists to inadvertently or deliberately manipulate their results must ultimately be targeted and addressed at the same specific behavioral level where the manipulation or errors are most likely to occur — during analyses, not just before or afterwards.

For this purpose, we should focus on finest level of research analysis there is: the level of statistical software. This requires problematizing the transparency problem as an economic problem to be solved.

\section{From hand-made to automated code}

Making research code available to the research public lessens transparency problems, but there is more to research replicability and integrity than providing author-created software programs. To reduce the incidence of errors and misbehaviors, transparency initiatives should target the use of statistical software itself. New software platforms used in data science are distinct from standard 
statistical programming languages, in that these new tools depend on simple point-and-click user interfaces, with the added benefit of being backward compatible with familiar command-based systems. Such cloud-based and open-source platforms automate the provision of source code, overcoming human-driven errors. Some software platforms such as Plot.ly are compatible with R, Python, JavaScript, and other Web applications, but condenses all necessary lines of code into a minimalistic point-and-click system.It goes further to automate making data visualizations open online in return for free cloud-based data hosting. Others, such as Narrative Science for Tableau use advanced natural language generation to automate the very text descriptions accompanying data visualizations. By providing automated text to authors, this innovation could rein in the temptation many authors may face to exaggerate their research findings. Natural language generation provides exciting opportunities to enable research to be more transparent, as summarized in Table 1. Researchers can cite data visualization descriptions that are generated by natural language generation verbatim to foster replication and avoid exaggerating their findings.

\section{Table 1. Using natural language generation to make research more transparent}

\begin{tabular}{|l|l|l|}
\hline $\begin{array}{l}\text { Step 1: Do data } \\
\text { visualization }\end{array}$ & $\begin{array}{l}\text { Step 2: Use natural } \\
\text { language generation to } \\
\text { automate the description of } \\
\text { the data visualization }\end{array}$ & $\begin{array}{l}\text { Step 3: Report the } \\
\text { automated description in } \\
\text { full, citing the software } \\
\text { used to generate the text. } \\
\text { Add any additional text if } \\
\text { necessary without } \\
\text { changing the original } \\
\text { automated text. Only the } \\
\text { automated text is cited. }\end{array}$ \\
\hline
\end{tabular}

Collectively, such software platforms limit research integrity compromises at multiple data analysis stages: enabling fewer mistakes (or inappropriate data manipulations); removing the need to perform variations of superficially-different statistical tests to yield a selective understanding of data or to focus selectively on certain parts of a dataset that yield sensitive results that are not representative. There is also a need for researchers to acknowledge and overcome arbitrary statistical and scientific judgments made during the analysis process itself ${ }^{2}$.

\section{Research Transparency as a Self-Control Problem}

I propose that a psychological self-control problem ${ }^{4}$ explains the mentality of most research misbehavior: economics scholars end up placing higher mental weights on scientific objectivity at an earlier date than at later dates - as they invest more energy on their datasets with a prior in their mind that may not always be easy to let go of. It may be easier to expect oneself to be objective before a study ensues than when a result collides with a prior expectation. To avoid succumbing to temptation, analysts need a tool that ties their hands to impartiality. The simple interfaces in newer software can obviously act as such psychological instruments - in other words, they prevent errors and malpractice by taking them out of scientists' personal discretions. By contrast, programming language-driven approaches enable blunders and misconduct by 
relying on researcher willpower, which, we must candidly admit, is unevenly distributed in any scientific community. Beyond the analysis of data, newer solutions can also nudge behavioral scientists by providing automated data visualization descriptions to overcome the likelihood of authors exaggerating their findings in their texts to take advantage of audiences that may be unfamiliar with or pay little attention to data analytics.

\section{Failures of complexity}

There is a huge barrier of time and effort investment to replicating research when one considers the mammoth human-created code that accompanies most research articles. Intricate commands inevitabliy have significant room for misinterpretation. Simply put, command-based programming was not meant to emphasize research integrity and it is too complex for this goal.

To illustrate, multiple research teams working on a single dataset have been known to provide results that vary widely and deeply contradict one another, showing low reproducibility of much work $^{5}$. A funder then becomes concerned about the validity of research writ large, the scientists on the project lose credibility in the eyes of their peers, as do those who work in the general discipline; and the public distrusts scientific experts. In the hands of scientists with impure agendas in performing a replication, human-created code only worsens integrity of the overall research community.

\section{Back to basics}

We must tackle the temptation to cheat at its core. I propose a detour from the use of humanprogrammed commands during econometric and statistical analyses. I recommend that automated software be used to carry out data-driven research for maximium transparency and integrity. Researchers would upload their data into such software platforms and only use pointand-click tools to analyze and manipulate their data - and would rely on computer-created code of the commands used, instead of creating and using their own. The visualizations would be then annotated with automated text generated by computer programs - to be contrasted with and to discipline human-created writings that might be prone to exaggerations or selective interpretations. In pre-analysis plans, researchers would justify the use of software based on how much it simplifies the proposed analyses and minimizes the chance of manipulation. Video clips like those popularized on social media could be used to document research analyses and replications to make them significantly easier to follow.

To expedite the analyses, such approaches should be implemented on anonymized data that is sufficiently cleaned but otherwise not analyzed. The approach is compatible with familiar research methods as quantitative social and behavioral science studies tend to evaluate new interventions with relevant experiments. In newer machine learning research, investigators could similarly use point and click software to gauge out-of-sample predictions using algorithm packages that match familiar commands. Potential study candidates include studies on personalized medicine (where genomic information is coupled with lifestyle, family history, and socioenvironmental factors as well as follow-up surveys to gauge behavioral changes to lessen disease risks and improve health outcomes), mobile phone survey research aimed at predicting 
economic behavior ${ }^{6}$ or phone-based experiments to understand subjective well-being ${ }^{7}$ (among populations where traditional paper surveys on sociodemographic factors are rare or unreliable), or investigations in scientific fields which use high-dimensional or"big" data that may be prone to manipulation.

The rise of machine learning in economics, (covered in the most recent issue of this Journal), also lends itself to the proposed approach, since machine learning tends to involve significantly more arbitrary choices than statistical causal inference approaches such as experiments and program evaluations. Machine learning researchers train models, cross-validate, evaluate out-ofsample predictions, and in some cases, tune parameters for improved predictions. Many analytical choices may be arbitrary and not always expected to highly transparent ${ }^{8}$. By standardizing the process, such research may become more transparent and over time. Some simple solutions aimed mostly or entirely at high-dimensional data include Microsoft Azure, Amazon Web Services, IBM, Oracle, and Google Cloud. Although targeted at businesses and not built with transparency intentions, the simplicity, dashboards and automation provided are, somewhat accidentally, a way to minimize transparency scientific issues that would benefit scientists that find such data environments applicable to their contexts.

Clearly, the use of minimal statistical software must allow scientists to continue to express their desires to be transparent, only more easily than ever before. Making visualizations and underlying data public on publication it would be appropriate. Journals could allow scholars to provide online weblinks to open data visualizations that would allow any replications to be relatively seamless. Such open visualization approaches should be seriously considered by academic scientists with interests in open data as they complement existing approaches ${ }^{9}$ for selfexamination and reflection in the pursuit of science across a growing number of fields. For example, data sharing and open data procedures are already affecting government supported scientific research by making scientific work more ethical and transparent ${ }^{10}$. A corresponding movement in the crowdsourced science space ${ }^{9}$ is another natural bedfellow of the proposed open visualizations which are embedded in newer data science solutions.

One reason why this issue will only grow in urgency is the emerging contexts of experiments and program evaluations using high-dimensional "big" data where human errors are likely to be even more relevant and potentially prevalent. The transition in medical science towards personalized medicine research ${ }^{11}$ opens the door for behavioral research that takes advantage of various sensors and trackers that are commonplace in mobile phones. The uncertain technological environments that host such initiatives ${ }^{12}$ require newer approaches in behavioral science experiments that are better at catching human errors, or better yet, ruling them out. However, there is a broader need for social and behavioral science researchers to become relatively comfortable with dilemmas that do not lend themselves to a tidy story ${ }^{13}$. One potential way to introduce flexibility into such discussions and interactions is by pursuing reform at the level of statistical software and encouraging the adoption of automation in research.

Much work remains to be done as far as reconciling the incentives of researchers with the general public is concerned. The primary goal of much social, behavioral science research are ultimately peer-review publications, fuelled by strong professional incentives. Unfortunately for the vast majority of quantitative social science fields where experiments and evaluations are 
routinely performed, journal editors and media professionals alike generally prefer to promote positive results over empirical findings that are not statistically significant or results which have negative implications. An unfortunate outcome of this phenomenon is that many researchers often become selective in their analyses as scholars anticipate low interest in findings that do not satisfy the demand for positive empirical arguments. The so-called "file-drawer problem"14,15 occurs whereby empirical results are stashed away from public view and ruled unworthy of publication effort when these findings appear to inadvertently confront a dominant body of work that is already published and widely cited.

Encouraging measures growing in popularity in the fight against irreproducible research ${ }^{16}$ include the growing use of pre-analysis plans ${ }^{17,2}$ which inform the scientific profession as well as the general public of the existence of a study in advance of the study actually being executed. Any changes made to the study protocol are also made public to enhance scientific transparency. Such knowledge may be invaluable for independent scholars interested in following up with authors on the status of such research in the future, while committing researchers to their original statistical specifications. Other heartening measures include the use of registered reports, which would free journal editors from a unique set of social pressures by pre-ordaining journal acceptance prior to being privy to the actual results ${ }^{18}$.

All of these increasingly well-documented hurdles facing transparency science: the file-drawer problem and the related problems of statistical specification searching, p-hacking and editorial injudiciousness can be reimagined as a consequence of the proposed psychological self-control problem where researchers, editors and other stakeholders may fall prey to their own psychological biases. The relative invisibility of this issue across disciplines has grave implications for how generalizable experimental results are. In particular, it is hard to know how representative published results are, relative to a number of related studies that never see the light of day. Similarly, it is currently unknown how many released scientific studies are actually replications of existing but invisible investigations that were unsuccessful. Another worrisome corollary is the question of how much research funds are inefficiently assigned to areas that are dead ends. As studies evolve through multiple conference presentations and journal submissions, several avenues avail themselves to tempt researchers to structure their findings to suit the popular perception of what arguments should be in the discipline.

Data science software can complement such initiatives by sharing the data and code in ways that encourage authors to add papers to their file drawers. For example, the Plot.ly software uses a JSON visualization schema that is a complete declarative format. This means that Plot.ly allows for creating and sharing interactive data visualizations that are portable across all languages and platforms that understand the schema and hosted for free online. This result means that researchers who use the Plot.ly system may make their research results open and available to the public, once journal permission is secured. This service also makes it easier for scholars interested in pursuing replications. By making such initiatives easier to accomplish with simple interfaces, we are being even more respectful of scarce scholarly time and energy.

Such simpler platforms also have the potential to be inclusive. Plot.ly for $\mathrm{R}$ for example, is an interactive open-source platform that creates graphs in a proprietary javascript library called plotlyjs, which allows data consumers to highlight data points by hovering, as well as zooming in 
and out while scrutinizing graphs and diagrams in an intuitive and transparent way, while maintaining a record of the changes made, all of which can be un-done in real-time to make discussions more transparent. Plot,ly for R works through the HTML widgets framework. This trait means that online consumers of data analytics may probe and validate many results independent of the original author once posted online. Simply printing a plot.ly object will render the chart locally in a web browser or in the R Studio viewer. Part of the reason why platforms such as Plot.ly scale is their ease of use and time-saving qualities, relative to the parent platforms they improve on. Importantly, an automated workflow of the data analytics is maintained by the system. Thus, scientists may allocate their attention more optimally and spend more effort interpreting results they have little control over, rather than using their efforts to maintain results they can more easily regulate.

\section{Simpler conversations}

There is no denying that such analytical shifts would be require open discussions within and across disciplinary fields. Demonstrations of automations' improvements on human judgements would help most scientists eventually transition to newer data science platforms, as has been the case in industry. Moreover, successful internalization of such tools is likely to require a combination of the simplified platforms with the underlying command-based languages for some, but with less of the latter as familiarity and understanding of the need for transparency grows.

Discussions around replications would likely become less antagonistic and more consistently constructive over time as scholarly orientation shifts from personalities to software. Much of the hostility and aggression that has surrounded scholarly replication discussions might, in part, have roots in subjective choices that are misread by other scholars. Due to significantly fewer degrees of freedom for misunderstandings provided by the next-generation of statistical software, the researchers' focus shifts from programming languages to discussing the implications of statistical results where they belong.

\section{Small steps}

Why aren't such platforms more widely used in economic science? An early ancestor of pointand-click programs, Microsoft's Excel, still works without the scientist having access to the source code record documenting the implemented commands, an omission which may make replications challenging. The command-based systems of today have improved on this software by making the human-computer interaction more transparent and fostering openness in science. Command-based software languages received much approval in science to help scholarship become more ethical, even if they necessarily traded convenience along the way. By using point-and-click tools that automate code, new data science tools present the best of both worlds.

Another reason why data science tools are relatively helpful is because their inclusion in the transparency agenda would help researchers better keep up with replicating the 75 randomized 
controlled trials performed on a daily basis in health experiments alone ${ }^{19}$. The use of such software can thus safeguard critical initiatives such as the Cancer Moonshot spearheaded by the White House which may spillover into a growth in the quantity of associated multidisciplinary human behavior research, which will almost certainly include economics research. There is obviously a huge investment of time and effort required to replicate the long and complex human-created code that accompanies so many research articles within and across sub-fields. This complex reality may be one reason why some scientists and researchers hesitate to engage with transparency, especially when the intricate programming they rely on inevitably leaves significant room for misinterpretation even when the analysis is sound. Bluntly put, commandbased programming was not meant to emphasize research integrity and it is currently too complex for this goal. Untangling code from another author by hand is certainly not the best use of medical scientists' scarce time and energy. Data science tools render this commonly-used approach increasingly unnecessary, however.

Data science tools can also minimize grave issues of subjectivity in scientific research. It is wellknown that contradictory results abound in behavioral, psychological and economic science. At worst, the public distrusts scientific experts when they give testimonies in court and other public forums as a result. In the hands of scientists with impure agendas such as personal vendettas in performing a replication, human-created code can distract from the aspirations of research transparency. These factors make the adoption of these minimalist data science tools urgent, as does the recent "fake news" phenomenon.

I do not mean to imply that if coding were done away with, problems of research transparency would instantaneously vaporize.

I accept that there are institutional, educational and even cultural hurdles that must be overcome for data science tools to help make academic research become more efficient. At the same time, the integrity of medical science and the safety of the public are too important for us to knowingly expose to the many human misjudgments that are pronounced in hand-based programming data environments. Such integrity problems will only accelerate rise with the advent of personalized medicine, which has already been identified to involve significant statistical complexities for research $^{3}$. The same is true of randomized controlled trials run in big data environments. Simpler platforms offer transparency benefits here also as they require fewer human-computer interactions.

I am enthusiastic about modern data science tools becoming as widespread in medical academic research as they are in the software technology sector, another setting where learning from experimentation is critical. Next-generational data science platforms often build on programming languages familiar to medical and other scientists while conveniently condensing code into a user-friendly point-and-click system. The machine-created code itself is easily downloaded separately where needed. By considerably simplifying user experiences, such tools obviously have the benefit of making human-led errors significantly less likely to occur. Just as importantly, such platforms make it harder for deliberate manipulations to occur in experimental analyses. 
There is no denying that such shifts require open discussions within and across scientific communities as well as journals and conferences with respect to questions like which specific software might work best for specific fields and types of research investigations. There is a need to nest this approach in the policy momentum towards a broader, more open research culture ${ }^{20}$. One common hesitation to using simple interfaces for science is that many researchers prefer to have a more hands-on data experience where they can personally verify that every step of a command has proceeded as intended. By their transparent user interfaces however, data science platforms encourage verification, if not manipulation. By ignoring our mechanical limits in the emerging context of personalized medical data and big data, I believe that we do a disservice to science. Automation frees us to focus on the design of better research questions and sharing our results with policy makers and the public.

Scholars must internalize the fact that momentous shifts in research cultures are required to protect scientific integrity. Although many complementary initiatives aimed at making research transparency have focused on the prevention of inappropriate scientific behavior, we also have to think about policies that are closer to a cure. Research communities should require the use such interfaces to help researchers hold ourselves to higher ethical standards.

Unfortunately, the growing replicability crisis tells us that the human-led errors and misgivings were only lessened by user-created commands to a minor degree. Thankfully, newer software combines the best of both perspectives, using point-and-click interfaces that are built on familiar programming environments while providing the source code of automated commands (in the familiar syntax of human-created code) to interested parties. Thus, the choice to cheat is much more effectively taken out of the hands of scientists in this approach. Die-hard Excel users will be glad to know that Plot.ly is compatible with that older software solution as well. Aspects of the method of minimalist methodology are comparable to a Occam's Razor ${ }^{21}$ for statistical software users (summarized in Table 2).

Table 2. An Occam's Transparency Razor.

Step 1: As part of a preanalysis plan, observe how many steps are required to perform an analysis from end-to-end across software platforms
Step 2: Pick, justify and use the appropriate software that provides the least human effort and minimizes questionable practices. Automate any data visualizations' text descriptions and compare such annotations with author-created text if possible.
Step 3: Document simplified instructions for record-keeping purposes reform 


\begin{tabular}{|c|c|c|}
\hline $\begin{array}{l}\text { Step 4: Use the same } \\
\text { software while replicating } \\
\text { analyses and compare with } \\
\text { other software solutions }\end{array}$ & $\begin{array}{l}\text { Step 5: Document } \\
\text { replication and identify } \\
\text { any observed nuances in } \\
\text { the research }\end{array}$ & $\begin{array}{l}\text { Step 6: Publish } \\
\text { visualizations and data } \\
\text { online with journal/outlet } \\
\text { permission for audience } \\
\text { engagement }\end{array}$ \\
\hline
\end{tabular}

An Occam's Transparency Razor: This means that economists and social scientists must depend on the simplest appropriate software used to analyze their data to uncompromisingly answer any research question. For transparency, researchers could rigorously justify the proposed software within the context of the proposed research question, so that the software that would require the least human effort would be chosen, with relatively scarce exceptions. Researchers may compare different statistical software packages for consistency as different software solutions may not always provide steady estimates for the same statistical analysis, particularly in behavioral or social science data that may have missing entries ${ }^{22}$ and other inconsistencies. Obviously, there is still a need to document the steps taken while conducting research, even with platforms that are straightforward to use. Where possible, data visualizations presented in online journals can include the embedded source data to foster transparency. Although this step imposes additional costs on smaller publishing firms, authors may be in a position to host such information on their personal websites with journal permission.

Most importantly, there remains a need for lessons to be shared across the behavioral sciences ${ }^{23-}$ 25 to maximize transparency in newer policy initiatives and avoid recreating the wheel, given a somewhat surprising growth of direct and indirect interest in research transparency, replications from a vast diversity of social and behavioral perspectives ${ }^{26-30}$ and the fact that there is something akin to a spike in the number of works answering the call for inclusiveness and transparency ${ }^{31-85}$. Integrative approaches with human-computer interaction (which is its own sub-field in computer science, but has caught the attention of a growing number of applied economists ${ }^{86-87}$ ), I argue, may have the spillover benefit of helping economics research to be more inclusive by focusing on pressure points within the research process.

Accepting that economists and social scientists are as human as everyone else might not sound like the best professional advice in a hyper-competitive world. Perhaps, stressing the distinction between what we do in our profession and who we are as people is one way to encourage scholars to partner with increasingly smart technologies that can help us to do better. By freeing up the time we invest in performing analyses and allowing us to be more physically and emotionally present with the people we care about, such tools may indirectly even help us to be better people over time. 


\section{References}

1. Announcement: Where Are The Data? Nature, 537, 138 (2016).

2. T. Miguel, et al., Promoting Transparency in Social Science Research. Science, 343, 3031 (2014).

3. Lewandowsky, Stephan, and Bishop, Dorothy, Research Integrity: Don't Let Transparency Damage Science. Nature, 529, 459-461(2016).

4. D. Kahneman, Thinking, Fast and Slow. (Farrar, Straus and Giroux, New York, 2011)..

5. M. R. Munafò, et. al., A manifesto for reproducible science. Nature Hum. Behav. 1, (0021), 1-9 (2017).

6. J. Blumenstock, G. Cadamuro, and R. On. Predicting poverty and wealth from mobile phone metadata. Science 350.6264, 1073-1076 (2015).

7. O. Heffetz, and M. Rabin. Conclusions regarding cross-group differences in happiness depend on difficulty of reaching respondents. Am. Ec. Rev. 103(7), 3001-3021 (2013).

8. Jin, Yaochu, and Bernhard Sendhoff. "Pareto-based multiobjective machine learning: An overview and case studies." IEEE Transactions on Systems, Man, and Cybernetics, Part C (Applications and Reviews) 38.3 (2008): 397-415.

9. R. Silberzahn, E., Uhlmann, Crowdsourced research: Many hands make tight work, Nature, 2015; 526, 189-191.

10. E. Warren, Strengthening Research through Data Sharing, New Engl J Med, 2016; 375, 401-403.

11. D.J. Hunter, Uncertainty in the Era of Precision Medicine, New Engl. J. Med, 375; 2016, 711-713.

12. R.S. Rudin, Bates, D.W., MacRae, C. Accelerating Innovation in Health IT, New Engl., J. Med, 2016; 375, 815-817.

13. A. Roy, et al. Encountering Poverty: Thinking and Acting in an Unequal World. (Univ. of California Pr., Oakland, 2016).

14. A. Franco, N. Malhotra, G. Simonovits, Publication bias in the social sciences: unlocking the file drawer." Science, 345, 1502-1505 (2014).

15. P.J. Gertler, Sebastian Martinez, Patrick Premand, Laura B. Rawlings, and Christel M. J. Vermeersch, Impact Evaluation in Practice, 2nd Ed. (World Bank, 2016). https://goo.gl/xcE8Mi

16. Open Science Collaboration. Estimating the reproducibility of psychological science. Science 349.6251 aac4716 (2015).

17. K. Casey, R. Glennerster, E. Miguel, Reshaping Institutions: Evidence on Aid Impacts Using a Pre-analysis Plan. Q. J. of Econ., 127, 1755-1812 (2012).

18. M. R. Munafò, et. al., A manifesto for reproducible science. Nature Hum. Behav. 1, (0021), 1-9 (2017). 
19. H. Bastian, P. Glasziou, I. Chalmers. Seventy-five trials and eleven systematic reviews a day: how will we ever keep up? PLoS Med, 7, e1000326-e1000326 (2010).

20. B.A. Nosek, et al. Promoting an open research culture. Science 348.6242 (2015): 14221425.

21. P. Domingos, "The Role of Occam's Razor in Knowledge Discovery" Data Mining and Knowledge Discovery, 3: 409. doi:10.1023/A:1009868929893 (1999).

22. Horton, Nicholas J., and Stuart R. Lipsitz. "Multiple imputation in practice: comparison of software packages for regression models with missing variables." Am. Stat.55.3 (2001): 244-254.

23. Hanke, Michael, et al. "Statistical learning analysis in neuroscience: aiming for transparency." Frontiers in neuroscience 3 (2010): 7.

24. Robert MacCoun and Saul Perlmutter. Blind analysis: Hide results to seek the truth. Nature (2015). 526, 187-189. doi:10.1038/526187a

25. Ferguson, Christopher J., and Moritz Heene. "A vast graveyard of undead theories publication bias and psychological science's aversion to the null." Perspectives on Psychological Science 7.6 (2012): 555-561.

26. Abreu, Maria, Henri L. F. de Groot, and Raymond J. G. M. Florax. "A Meta-Analysis of $\beta$ - Convergence: The Legendary 2\%.” Journal of Economic Surveys 19 (2005): 389-420. doi:10.1111/j.0950-0804.2005.00253.x.

27. Anderson, Richard G., and William G. Dewald. 1994. "Replication and Scientific Standards in Applied Economics a Decade after the Journal of Money, Credit and Banking Project.” Federal Reserve Bank of St. Louis Review, no. Nov: 79-83.

28. Christensen, Garret and Edward Miguel (2017). "Transparency, Reproducibility, and the Credibility of Economics Research." Journal of Economic Literature, forthcoming.

29. Anderson, Richard G., William H. Greene, B. D. McCullough, and H. D. Vinod. 2008. "The Role of Data/Code Archives in the Future of Economic Research." Journal of Economic Methodology 15 (1): 99-119. doi:10.1080/13501780801915574.

30. Andreoli-Versbach, Patrick, and Frank Mueller-Langer. 2014. "Open Access to Data: An Ideal Professed but Not Practised.” Research Policy. Accessed August 29. doi:10.1016/j.respol.2014.04.008. 75

31. Backhouse, Roger E., and Mary S. Morgan. 2000. "Introduction: Is Data Mining a Methodological Problem?” Journal of Economic Methodology 7 (2): 171-81. doi:10.1080/13501780050045065.

32. Angrist, Joshua D, and Jörn-Steffen Pischke. 2010. "The Credibility Revolution in Empirical Economics: How Better Research Design Is Taking the Con out of Econometrics." Journal of Economic Perspectives 24 (2): 3-30. doi:10.1257/jep.24.2.3.

33. Annas, George J. 2003. "HIPAA Regulations - A New Era of Medical-Record Privacy?" New England Journal of Medicine 348 (15): 1486-90. doi:10.1056/NEJMlim035027. 
34. Aiken, Alexander M., Calum Davey, James R. Hargreaves, and Richard J. Hayes. 2015. "ReAnalysis of Health and Educational Impacts of a School-Based Deworming Programme in Western Kenya: A Pure Replication.” International Journal of Epidemiology, July, dyv127. doi:10.1093/ije/dyv127.

35. Allcott, Hunt, and Dmitry Taubinsky. 2015. "Evaluating Behaviorally Motivated Policy: Experimental Evidence from the Lightbulb Market." American Economic Review 105 (8): 2501-38. doi:10.1257/aer.20131564.

36. Anderson, Christopher J., Štěpán Bahník, Michael Barnett-Cowan, Frank A. Bosco, Jesse Chandler, Christopher R. Chartier, Felix Cheung, et al. 2016. "Response to Comment on 'Estimating the Reproducibility of Psychological Science.'” Science 351 (6277): 10371037. doi:10.1126/science.aad9163.

37. Anderson, Melissa S., Brian C. Martinson, and Raymond De Vries. 2007. "Normative Dissonance in Science: Results from a National Survey of U.S. Scientists." Journal of Empirical Research on Human Research Ethics 2 (4): 3-14. doi:10.1525/jer.2007.2.4.3.

38. Anderson, Michael L. 2008. "Multiple Inference and Gender Differences in the Effects of Early Intervention: A Reevaluation of the Abecedarian, Perry Preschool, and Early Training Projects.” Journal of the American Statistical Association 103 (484): 1481- 95. doi:10.1198/016214508000000841.

39. Ashenfelter, Orley, and Michael Greenstone. 2004. "Estimating the Value of a Statistical Life: The Importance of Omitted Variables and Publication Bias." Princeton University, Department of Economics, Center for Economic Policy Studies., Working Papers: 105, 2004. http://search.proquest.com/econlit/docview/56626726/1A493319C9B3407FPQ/ 4 ? accountid=14496.

40. Ashenfelter, Orley, Colm Harmon, and Hessel Oosterbeek. 1999. "A Review of Estimates of the Schooling/Earnings Relationship, with Tests for Publication Bias." Princeton, Department of Economics - Industrial Relations Sections, Princeton, Department of Economics - Industrial Relations Sections, 1999. http://search.proquest.com/econlit/docview/56307618/5A788ADBA14C479EPQ/ 2? accountid=14496.

41. Bai, Liang, Benjamin Handel, Edward Miguel, and Gautam Rao. 2015. "Self-Control and Chronic Illness: Evidence from Commitment Contracts for Doctor Visits." Unpublished Manuscript. UC Berkeley.

42. Baicker, Katherine, Amy Finkelstein, Jae Song, and Sarah Taubman. 2014. "The Impact of Medicaid on Labor Market Activity and Program Participation: Evidence from the Oregon Health Insurance Experiment." American Economic Review 104 (5): 322-28. doi:10.1257/aer.104.5.322.

43. Baicker, Katherine, Sarah L. Taubman, Heidi L. Allen, Mira Bernstein, Jonathan H. Gruber, Joseph P. Newhouse, Eric C. Schneider, Bill J. Wright, Alan M. Zaslavsky, and Amy N. Finkelstein. 2013. "The Oregon Experiment - Effects of Medicaid on Clinical Outcomes." New England Journal of Medicine 368 (18): 1713-22. doi:10.1056/NEJMsa1212321. 
44. Bakkensen, Laura A., and William Larson. 2014. "Population Matters When Modeling Hurricane Fatalities." Proceedings of the National Academy of Sciences of the United States of America 111 (50): E5331-32. doi:10.1073/pnas.1417030111.

45. Bateman, Ian, Daniel Kahneman, Alistair Munro, Chris Starmer, and Robert Sugden. 2005. "Testing Competing Models of Loss Aversion: An Adversarial Collaboration." Journal of Public Economics, The Experimental Approaches to Public Economics, 89 (8): 1561-80. doi:10.1016/j.jpubeco.2004.06.013.

46. Begg C, Cho M, Eastwood S, and et al. 1996. "Improving the Quality of Reporting of Randomized Controlled Trials: The Consort Statement." JAMA 276 (8): 637-39. doi:10.1001/jama.1996.03540080059030.

47. Bellavance, François, Georges Dionne, and Martin Lebeau. 2009. "The Value of a Statistical Life: A Meta-Analysis with a Mixed Effects Regression Model." Journal of Health Economics 28 (2): 444-64. doi:10.1016/j.jhealeco.2008.10.013. 76

48. Benjamini, Yoav, and Yosef Hochberg. 1995. "Controlling the False Discovery Rate: A Practical and Powerful Approach to Multiple Testing." Journal of the Royal Statistical Society. Series B (Methodological) 57 (1): 289-300.

49. Benjamini, Yoav, Abba M. Krieger, and Daniel Yekutieli. 2006. "Adaptive Linear Stepup Procedures That Control the False Discovery Rate." Biometrika 93 (3): 491-507. doi:10.1093/biomet/93.3.491.

50. Benjamini, Yoav, and Daniel Yekutieli. 2001. "The Control of the False Discovery Rate in Multiple Testing under Dependency." The Annals of Statistics 29 (4): 1165-88.

51. Berge, Lars Ivar Oppedal, Kjetil Bjorvatn, Simon Galle, Edward Miguel, Daniel N. Posner, Bertil Tungodden, and Kelly Zhang. 2015. "How Strong Are Ethnic Preferences?" Working Paper 21715. National Bureau of Economic Research. http://www.nber.org/papers/w21715.

52. Berger, Ulrich. 2009. "The Convergence of Fictitious Play in Games with Strategic Complementarities: A Comment." https://mpra.ub.uni-muenchen.de/20241/.

53. Bernanke, Ben S. 2004. "Editorial Statement.” The American Economic Review 94 (1): 404- 404.

54. Bertrand, Marianne, and Sendhil Mullainathan. 2004. "Are Emily and Greg More Employable Than Lakisha and Jamal? A Field Experiment on Labor Market Discrimination.” The American Economic Review 94 (4): 991-1013. doi:10.1257/0002828042002561.

55. Bland, J. M., and D. G. Altman. 1995. "Multiple Significance Tests: The Bonferroni Method." BMJ : British Medical Journal 310 (6973): 170.

56. Bohannon, John. 2016. "About 40\% of Economics Experiments Fail Replication Survey.” Science, March. doi:10.1126/science.aaf4141.

57. Bontemps, Christophe, and Grayham E. Mizon. 2008. "Encompassing: Concepts and Implementation*." Oxford Bulletin of Economics and Statistics 70 (December): 721-50. doi:10.1111/j.1468-0084.2008.00528.x. 
58. Boutron, Isabelle, David Moher, Douglas G. Altman, Kenneth F. Schulz, and Philippe Ravaud. 2008. "Extending the CONSORT Statement to Randomized Trials of Nonpharmacologic Treatment: Explanation and Elaboration." Annals of Internal Medicine 148 (4): 295-309. doi:10.7326/0003-4819-148-4-200802190-00008.

59. Broad, William, and Nicholas Wade. 1983. Betrayers of the Truth. Simon and Schuster. Brodeur, Abel, Mathias Le, Marc Sangnier, and Yanos Zylberberg. 2016. "Star Wars: The Empirics Strike Back.” American Economic Journal: Applied Economics 8 (1): 132.

60. Burnside, Craig, and David Dollar. 2000. "Aid, Policies, and Growth." The American Economic Review 90 (4): 847-68. —. 2004. "Aid, Policies, and Growth: Reply." The American Economic Review 94 (3): 781-84.

61. Calvert M, Blazeby J, Altman DG, and et al. 2013. "Reporting of Patient-Reported Outcomes in Randomized Trials: The Consort pro Extension.” JAMA 309 (8): 814-22. doi:10.1001/jama.2013.879.

62. Camfield, Laura, and Richard Palmer-Jones. 2013. "Three 'Rs' of Econometrics: Repetition, Reproduction and Replication.” Journal of Development Studies 49 (12): 1607-14. doi:10.1080/00220388.2013.807504.

63. Campbell, Marion K., Diana R. Elbourne, and Douglas G. Altman. 2004. "CONSORT Statement: Extension to Cluster Randomised Trials.” BMJ 328 (7441): 702-8. doi:10.1136/bmj.328.7441.702.

64. Campbell, Marion K., Gilda Piaggio, Diana R. Elbourne, and Douglas G. Altman. 2012. "Consort 2010 Statement: Extension to Cluster Randomised Trials." BMJ 345 (September): e5661. doi:10.1136/bmj.e5661.

65. Campolieti, Michele, Morley Gunderson, and Chris Riddell. 2006. "Minimum Wage Impacts from a Prespecified Research Design: Canada 1981-1997." Industrial Relations: A Journal of Economy and Society 45 (2): 195-216. doi:10.1111/j.1468232X.2006.00424.X.

66. Card, David. 1992. "Do Minimum Wages Reduce Employment? A Case Study of California, 1987-89." Industrial \& Labor Relations Review 46 (1): 38-54. doi:10.1177/001979399204600104.

67. Card, David, Raj Chetty, Martin Feldstein, and Emmanuel Saez. 2010. "Expanding Access to Administrative Data for Research in the United States." 112. NSF SBE 2020. http://www.nsf.gov/sbe/sbe_2020/2020_pdfs/Card_David_112.pdf.

68. Card, David, and Alan B. Krueger. 1994. "Minimum Wages and Employment: A Case Study of the Fast-Food Industry in New Jersey and Pennsylvania." The American Economic Review 84 (4): 772-93.

69. Carey, Benedict. 2011. "Noted Dutch Psychologist, Stapel, Accused of Research Fraud." The New York Times, November 2, sec. Health / Research. http://www.nytimes.com/2011/11/03/health/research/noted-dutchpsychologist-stapelaccused-of-research-fraud.html. 
70. Casey, Katherine, Rachel Glennerster, and Edward Miguel. 2012. "Reshaping Institutions: Evidence on Aid Impacts Using a Preanalysis Plan." The Quarterly Journal of Economics 127 (4): 1755-1812. doi:10.1093/qje/qje027.

71. Casselman, Ben. 2012. "Economists Set Rules on Ethics.” Wall Street Journal, January 9, sec. Careers. 78 http://www.wsj.com/articles/SB100014240529702034369045771489404106679 70.

72. Chambers, Christopher. 2013. "Registered Reports: A New Publishing Initative at Cortex." Cortex 49: 609-10. doi:http://dx.doi.org/10.1016/j.cortex.2012.12.016.

73. Chambers, Christopher D., Eva Feredoes, Suresh D. Muthukumaraswamy, and Peter J. Etchells. 2014. "Instead of 'playing the Game' It Is Time to Change the Rules: Registered Reports at AIMS Neuroscience and beyond." AIMS Environmental Science 1 (1): 4-17. doi:10.3934/Neuroscience.2014.1.4.

74. Chang, Andrew C., and Phillip Li. 2015. "Is Economics Research Replicable? Sixty Published Papers from Thirteen Journals Say 'Usually Not." Finance and Economics Discussion Series 2015-83. Board of Governors of the Federal Reserve System (U.S.). http://econpapers.repec.org/paper/fipfedgfe/2015-83.htm.

75. Christensen, B., and S. Christensen. 2014. "Are Female Hurricanes Really Deadlier than Male Hurricanes?" Proceedings of the National Academy of Sciences 111 (34): E349798. doi:10.1073/pnas.1410910111.

76. Ciccone, Antonio. 2011. "Economic Shocks and Civil Conflict: A Comment." American Economic Journal: Applied Economics 3 (4): 215-27. doi:10.1257/app.3.4.215.

77. Clemens, Michael. 2015. "The Meaning of Failed Replications: A Review and Proposal." 399. Center for Global Development Working Paper. http://www.cgdev.org/publication/meaning-failed-replications-review-andproposalworking-paper-399.

78. Coffman, Lucas C., and Muriel Niederle. 2015. "Pre-Analysis Plans Have Limited Upside, Especially Where Replications Are Feasible.” Journal of Economic Perspectives 29 (3): 81-98.

79. Cohen-Cole, Ethan, Steven Durlauf, Jeffrey Fagan, and Daniel Nagin. 2009. "Model Uncertainty and the Deterrent Effect of Capital Punishment." American Law and Economics Review 11 (2): 335-69. doi:10.1093/aler/ahn001. "Correspondence: David H

80. Autor and Bruno S. Frey." 2011. Journal of Economic Perspectives 25 (3): 239-40.

81. Cowen, Tyler, and Alex Tabarrok. 2016. "A Skeptical View of the National Science Foundation's Role in Economic Research.” Journal of Economic Perspectives 30 (3): 235-48. doi:10.1257/jep.30.3.235.

82. Croke, Kevin, Joan Hamory Hicks, Eric Hsu, Michael Kremer, and Edward Miguel. 2016. "Does Mass Deworming Affect Child Nutrition? Meta-Analysis, CostEffectiveness, and Statistical Power." Working Paper 22382. National Bureau of Economic Research. http://www.nber.org/papers/w22382.

83. Dahl Rasmussen, Ole, Nikolaj Malchow-Møller, and Thomas Barnebeck Andersen. 2011. "Walking the Talk: The Need for a Trial Registry for Development Interventions." 
Journal of Development Effectiveness 3 (4): 502-19.

doi:10.1080/19439342.2011.605160.

84. Dal-Ré, Rafael, John P. Ioannidis, Michael B. Bracken, Patricia A. Buffler, An-Wen Chan, Eduardo L. Franco, Carlo La Vecchia, and Elisabete Weiderpass. 2014. "Making Prospective Registration of Observational Research a Reality." Science Translational Medicine 6 (224): 224cm1-224cm1. doi:10.1126/scitranslmed.3007513. 79

85. Zimmermann, Christian. 2015. "On the Need for a Replication Journal.” Working Paper Series, no. No. 2015-016 (August). http://research.stlouisfed.org/wp/more/2015- 016/.

86. Aker, Jenny C., Ishita Ghosh, and Jenna Burrell (2016). The promise (and pitfalls) of ICT for agriculture initiatives. Agricultural Economics 47, 35-48.

87. Opoku-Agyemang, K. 2015. "Mobilizing Impact Evaluations: Mobile Survey MicroExperiments for Sustainable Development." Evaluation Matters: Emerging Solutions to Development Challenges Vol. 1. African Development Bank.

\section{Author Information}

\section{Affiliations}

Human-Computer Interaction and Social Computing Research Area, Cornell Tech, 111 $8^{\text {th }}$ Avenue, \#302, New York, NY 10011, USA

Center for Effective Global Action, Department of Agricultural and Resource Economics, University of California, Berkeley, 207 Giannini Hall, Berkeley, CA 94720, USA

International Growth Centre, London School of Economics and Political Science, 32 Lincoln Inn Fields, Houghton Street, London, WC2A 2AE, UK

\section{Competing Interests}

The research was funded by National Science Foundation under Grant No. IIS-1054332.

\section{Corresponding author}

Correspondence to: Kweku Opoku-Agyemang (weku@ berkeley.edu $)$ 